\title{
Desafios do planejamento e desenvolvimento do turismo cultural em centros históricos tombados: o caso de Penedo-Alagoas
}

\author{
Challenges of the planning and development of cultural tourism in historical \\ centers taken by heritage: the case of Penedo-Alagoas
}

Silvana Pirillo Ramos[a] (1)

[a] Universidade Federal de Alagoas (UFAL), Unidade de Ensino Penedo, Curso de Turismo, Penedo, AL, Brasil

Como citar: Ramos, S. P. (2019). Desafios do planejamento e desenvolvimento do turismo cultural em centros históricos tombados: o caso de Penedo-Alagoas. urbe. Revista Brasileira de Gestão Urbana, 11, e20180075. https://doi.org/10.1590/2175-3369.011.e20180075

\section{Resumo}

Estudo de caso do planejamento e desenvolvimento do turismo cultural na cidade de Penedo, Estado de Alagoas, que foi tombada em 1995 pelo Instituto do Patrimônio Histórico e Artístico Nacional (IPHAN) e contemplada com o Programa Monumenta (2002-2009) e o Programa de Aceleração do Crescimento das Cidades Históricas (PAC-CH) em 2013, ambos com propostas de conservar e restaurar bens culturais imóveis, possibilitando novos usos e promovendo melhorias de infraestrutura, preservação do patrimônio cultural e desenvolvimento do turismo cultural. Como os recursos aplicados em Penedo não resultaram na dinamização do turismo e os programas não conjugaram recuperação e preservação do patrimônio cultural com desenvolvimento econômico, fez-se uma análise das políticas implementadas, com consulta a documentos da gestão pública, desde 2002, e entrevistas com gestores públicos para identificar entraves no processo de planejamento e gestão. Verificou-se que houve a redução do turismo cultural, a restauração e a conservação do patrimônio cultural, sem preocupações com um planejamento interpretativo em uma gestão conjunta e participativa, para a construção de um produto que pudesse atender às demandas de um turismo da economia da experiência. Dessa forma, identificou-se o desaproveitamento dos recursos investidos pelo PAC-CH e pelo Programa Monumenta no que se refere à promoção do centro histórico tombado como elemento potencial para dinamizar o desenvolvimento econômico, social e cultural da localidade.

Palavras-chave: Turismo cultural. Planejamento interpretativo. Educação patrimonial. Programa de revitalização do patrimônio. Patrimônio cultural.

\section{Abstract}

This is a case study of the planning and development of Cultural Tourism in Penedo-AL, registered in 1995 by the National Historical and Artistic Heritage Institute (IPHAN) and contemplated with the Monumenta Program (2002-2009) and the Growth Acceleration Program for Historical Cities (PAC-CH) in 2013, both programs with proposals to conserve and restore immovable cultural property, enabling new uses, promoting infrastructure improvement, preserving cultural heritage and developing the 
Cultural Tourism. As the resources applied in Penedo did not result in the promotion of tourism and the programs did not combine recuperation and preservation of the cultural heritage with economic development, an analysis of the implemented policies was performed, with reference to the documents of the public management since 2002 and interviews with managers to identify obstacles to the planning and management process. The reduction of Cultural Tourism has been reduced to the restoration and preservation of cultural heritage, without concerns with interpretive planning in joint and participative management, for the construction of a product that can meet the demands of a tourist of the economy of experience. In this way, the resources invested both by PAC-CH and the Monumenta Program were identified as a potential element to boost the economic, social and cultural development of the locality.

Keywords: Cultural tourism. Interpretive planning. Patrimonial education. Patrimony revitalization program. Cultural heritage.

\section{Introdução}

Planejar e desenvolver o turismo cultural em centros históricos tombados tem sido um grande desafio para as gestões públicas de turismo e patrimônio cultural no Brasil. Muitos projetos de revitalização de centros históricos não conseguem promover transformações significativas na área de abrangência que resultem em melhoria da qualidade de vida da população local, possibilitando sua inclusão em atividades econômicas, como o turismo, e aumentando a conscientização sobre a importância da preservação do patrimônio cultural. A problemática é somada ainda ao desperdício dos recursos financeiros e traz à cena a urgência da investigação dos elementos que inviabilizam o desenvolvimento do turismo cultural e dificultam o cumprimento das metas estabelecidas.

Entre as dificuldades estão a adequação dos atrativos às demandas específicas de vivências e experiências do turista de motivações culturais e a inserção da população local na atividade econômica, de forma a garantir a preservação e a sustentabilidade do próprio patrimônio.

Este artigo consiste em um estudo de caso do processo de planejamento e desenvolvimento do turismo cultural em Penedo, cidade com 60.378 habitantes (IBGE, 2010), localizada ao sul do Estado de Alagoas, às margens do Rio São Francisco, que foi tombada pelo Instituto do Patrimônio Histórico e Artístico Nacional (IPHAN) em 1995, com o reconhecimento de um patrimônio artístico-cultural de valor, cenário de acontecimentos significativos na história do Brasil colonial.

A inserção de Penedo nas relações do comércio fluvial proporcionou-lhe prosperidade econômica e resultou na presença de uma arquitetura eclética com diversidade de momentos representados em seu sítio histórico. As marcas dos colonizadores portugueses e holandeses e dos missionários franciscanos foram deixadas na arquitetura barroca, principalmente dos conventos e das igrejas. A cidade seguiu prospera até a segunda metade do século XX, quando o transporte fluvial entrou em decadência com a construção de rodovias e ferrovias em Alagoas (Diégues, 2006).

Tendo em vista tais características, o desenvolvimento econômico passa a ser pensado a partir da dinamização de diferentes usos do patrimônio cultural, por meio de um processo de reabilitação do centro histórico tombado. Atualmente, cerca de $90 \%$ dos turistas que visitam o Estado de Alagoas são atraídos para o litoral, sendo predominante o turismo de sol e praia, mas o Plano Municipal Estratégico de Desenvolvimento do Turismo e o Plano Estadual de Desenvolvimento trazem como meta o fomento ao turismo cultural, sendo a cidade de Penedo uma das prioridades. 
Em 2002, Penedo foi contemplado pelo Programa Monumenta ${ }^{1}$, considerado, em suas origens, o mais significativo programa do país, com maior volume de recursos, na área de recuperação de sítios históricos, e, em 2013, com o Programa de Aceleração do Crescimento das Cidades Históricas $(\mathrm{PAC}-\mathrm{CH})^{2}$. Ambos os programas têm como propostas conservar e restaurar os bens culturais imóveis, possibilitando novos usos e promovendo melhorias da infraestrutura e dinamização de atividades econômicas, como o turismo, considerado alternativa para a sustentabilidade das áreas preservadas. São programas focados em ações que se voltam para o desenvolvimento do turismo cultural como estratégia para a sustentação e a manutenção do patrimônio revitalizado.

Por outro lado, verifica-se que, mesmo com os recursos injetados pelos programas de revitalização do patrimônio e com parte significativa de bens imóveis já restaurada pelo Programa Monumenta, o objetivo do desenvolvimento do turismo cultural não foi atingido, e não houve dinamização do turismo em Penedo. Dessa forma o Programa Monumenta fracassou em seus objetivos, principalmente no que se refere à autossustentabilidade do patrimônio, e não conseguiu conjugar sua recuperação e preservação com desenvolvimento econômico (Ramos, 2015).

Os principais monumentos do centro histórico foram revitalizados pelo Programa Monumenta sem dinamização de novos usos, e, atualmente, há dificuldades para obtenção de recursos para manutenção deles, pois são de alto custo e totalmente dependentes de recursos públicos.

O PAC-CH trouxe para o município a proposta do patrimônio cultural como eixo indutor e estruturante, com objetivo de contribuir para o ordenamento urbano e reverter o subaproveitamento do potencial econômico e simbólico. A proposta é o deslocamento do paradigma da preservação para o da conservação e da reabilitação, propondo o desafio da integração das ações de preservação do patrimônio com estratégias de desenvolvimento local (Castriota et al., 2010). Mesmo com esses princípios, o desenvolvimento do programa, desde 2013, não revela, em Penedo, ações efetivas para o desenvolvimento do turismo cultural, mas sim somente ações pontuais relativas à recuperação de monumentos históricos no que se refere aos aspectos físicos e estruturais, contrariando as metas do programa.

Diante da problemática, esta pesquisa tem como objetivo analisar o processo de planejamento e desenvolvimento do turismo cultural e os entraves que comprometem a consolidação de um destino como turístico cultural, a partir da compreensão das etapas necessárias para um planejamento interpretativo e das políticas propostas e efetivamente implementadas para seu desenvolvimento.

A pesquisa se desenvolveu a partir de levantamento e análise de documentos de Penedo, como o Plano Municipal de Diretrizes Estratégicas para o Turismo e o Plano Diretor Municipal, relatórios de trabalho do IPHAN relativos ao PAC-CH e ao Programa Monumenta, atas de reuniões do Conselho Municipal de Turismo (COMTUR) e do Fundo de Preservação do Patrimônio (FUNPATRI) e documentos do Estado de Alagoas, como o Plano Estadual de Turismo e o Plano de Desenvolvimento Estadual.

Foram realizadas entrevistas com os gestores de turismo e de patrimônio cultural atuantes em Penedo entre 2002 e 2017 (secretário de Turismo, secretário de Cultura, secretário de Planejamento e Infraestrutura, coordenador municipal do Programa Monumenta, coordenador municipal do PAC-CH, coordenadores do IPHAN na gestão do PAC e do Programa Monumenta) e com membros representantes do Conselho Municipal de Turismo e FUNPATRI (representantes do trade turístico e

\footnotetext{
10 Programa Monumenta teve início em 2000 (em Penedo, em 2002), contemplando 26 municípios selecionados a partir de características do patrimônio cultural e seu significado para a história do Brasil. Seus objetivos consistem em: preservar áreas prioritárias do patrimônio histórico e artístico urbano; estimular ações que aumentem a consciência da população sobre a importância de se preservar o acervo existente; estabelecer critérios de conservação; aperfeiçoar a gestão do patrimônio; estimular projetos que viabilizem as utilizações econômicas, culturais e sociais das áreas em recuperação no âmbito do projeto; e aumentar a consciência da população com relação à importância da preservação do patrimônio (Brasil, 2012).

2 o Programa de Aceleração do Crescimento das Cidades Históricas começou a ser implementado em 2009 (em Penedo, em 2013), envolvendo todos os agentes intergovernamentais, com o investimento de R 140 milhões destinados a projetos em cidades históricas. 0 principal objetivo consiste em promover a requalificação urbanística dos sítios históricos e estimular usos que garantam seu desenvolvimento econômico, social e cultural (Brasil, 2009).
} 
universidades). A opção foi pela entrevista semiestruturada, por se tratar de um instrumento de coleta de dados que permite combinar perguntas fechadas e abertas, em um roteiro previamente elaborado, dando possibilidade para o entrevistado discorrer sobre o tema proposto, sem respostas ou condições prefixadas, sendo, dessa forma, estimulado a pensar e a se expressar livremente acerca do assunto abordado. Todas as entrevistas foram gravadas e transcritas, e, a partir da criação de categorias, foi feita a análise de conteúdo do discurso.

Trata-se de uma pesquisa de abordagem qualitativa que, por sua natureza, responde, segundo Minayo (1994), a um nível de realidade que não pode ser quantificado e que tem o propósito de aprofundamento e compreensão dos fenômenos que se propõe estudar, construindo interpretações na perspectiva dos próprios sujeitos que participam da situação, sem se preocupar com representatividade numérica ou com generalizações estatísticas. Dessa forma, os dados coletados, por serem provenientes do estímulo ao livre pensamento e da expressão dos entrevistados sobre o tema proposto, trazem diferentes percepções sobre o fenômeno e proporcionam uma dimensão de análise que abarca múltiplas interpretações.

O cenário de fracasso da proposta de turismo cultural do único município contemplado no Estado de Alagoas pelos dois maiores e mais significativos programas de revitalização do patrimônio cultural do país bem como os investimentos de recursos sem resultados efetivos das políticas públicas justificam a necessidade do desenvolvimento desta pesquisa, tornando necessária a análise das dificuldades para que a atividade econômica do turismo possa se desenvolver, sustentando-se nos atrativos do patrimônio cultural e possibilitando a esse patrimônio a autossustentabilidade.

\section{Planejamento do furismo cultural}

\section{A Organização Mundial de Turismo (OMT, 2001, p. 23) define o turismo cultural como}

[...] o movimento de pessoas, devido essencialmente a motivos culturais como viagens de estudo, viagens a festivais ou outros eventos artísticos, visitas a sítios e monumentos, viagens para estudar a natureza, a arte, o folclore as peregrinações.

A Carta de Turismo Cultural do Conselho Internacional dos Monumentos e Sítios (ICOMOS, 1999, p.4) o define como "[...] uma forma de turismo que tem por objeto central o conhecimento de monumentos, sítios históricos e artísticos ou qualquer elemento do património cultural”. A Carta coloca a possibilidade da preservação do patrimônio cultural associada ao desenvolvimento do turismo, considerando que o turismo cultural exerce um efeito realmente positivo sobre esse patrimônio e contribui para satisfazer seus próprios fins, como sua manutenção e sua proteção.

Esta forma de turismo justifica, de fato, os esforços que tal manutenção e proteção exigem da comunidade humana, devido aos benefícios socioculturais e econômicos que comporta para toda a população implicada (ICOMOS, 1999, p. 3).

O turismo cultural é considerado um aliado na conservação do patrimônio, visto que pode ampliar o conhecimento do público em geral sobre esse patrimônio, assim como as possibilidades de acesso e, consequentemente, a sensibilização e o envolvimento com o despertar do sentimento de preservação. 0 patrimônio cultural pode tornar-se autossustentável com o aproveitamento das vantagens econômicas para a sua conservação, criando recursos financeiros, desenvolvendo a educação e reorientando as políticas.

O ICOMOS trabalha o conceito de patrimônio referindo-se ao meio ambiente natural e cultural. Dessa forma, patrimônio cultural

[...] engloba as noções de paisagem, de conjuntos históricos, de sítios naturais e construídos, bem como as noções de biodiversidade, de acervos culturais, de práticas culturais, tradicionais ou atuais e de conhecimento (ICOMOS, 1999, p. 2). 
No Brasil, o turismo cultural é apontado pelas políticas como alternativa para geração de emprego e renda, principalmente em localidades distantes do litoral que não podem explorar o turismo de sol e praia, predominante no país. Trata-se de um turismo considerado como sustentável por promover a valorização da cultura e a melhoria da qualidade de vida da população local e elencado como aquele que se contrapõe a um turismo de massa, o qual é reconhecido por ocasionar inúmeros impactos negativos.

O desenvolvimento do turismo cultural é uma alternativa para que as cidades possam se inserir em um cenário de competitividade global, tornando-se agentes do processo, projetando a imagem necessária para atrair turistas, agências multilaterais e investidores, por meio de estratégias de marketing, atendendo à necessidade de "[...] aumentar a capacidade de atração do produto cidade" (Sánchez, 1999, s/p).

O turismo no início do novo milênio registra características históricas diferentes do turismo massivo de meados do século XX, a iniciar-se pela alteração nos gostos e nas preferências da demanda dos turistas, caracterizados pela busca de novas experiências, em vez de somente novos produtos e serviços, que conduzem à ampliação territorial do mercado turístico (Beni, 2004).

O Ministério do Turismo do Brasil trabalha o turismo cultural, atualmente, tendo como base as premissas da economia da experiência, que considera um mercado com valores diferenciados e um consumidor com novas necessidades estruturadas em sentimentos, vivências e experiências.

Vivenciar significa sentir, captar a essência, e isso se concretiza em duas formas de relação do turista com a cultura ou algum aspecto cultural: a primeira refere-se às formas de interação para conhecer, interpretar, compreender e valorizar aquilo que é o objeto da visita; a segunda corresponde às atividades que propiciam experiências participativas, contemplativas e de entretenimento, que ocorrem em função do atrativo motivador da visita (Brasil, 2010, p. 28).

As demandas são de um turista que exige muito mais que uma simples visita a um atrativo turístico, sendo a decisão de compra mobilizada por informações amplas obtidas no universo virtual e compartilhadas nas redes sociais. "Na Economia da Experiência os conceitos, ideias e imagens e não mais bens materiais se tornam os verdadeiros itens de valor" (Rifkin, 2001, p. 4).

Trata-se de uma tendência econômica mundial que está sendo seguida por aqueles que querem inovar nos processos de formação e comercialização de produtos, especialmente na atividade turística (Brasil, 2014). No turismo, a vantagem competitiva se estrutura justamente por aquele que conseguir oferecer as emoções memoráveis e as experiências mais significativas, bem como revelar maior sensibilidade para identificar as necessidades do cliente (Santana Talavera, 2003). Dessa forma, o turismo cultural assume-se como um nicho de mercado, em que as motivações primárias são regidas pela atratividade dos sítios culturais, dos eventos, da expressão das atrações em si e das experiências associadas, e que, para se desenvolver, depende de um processo de planejamento interpretativo (Craik, 1997).

Entre os entraves para o desenvolvimento do turismo cultural está a sua redução apenas à restauração e à conservação do patrimônio cultural da localidade, sem maiores preocupações com a construção do que seria o produto turístico e sua gestão, o que torna necessário repensar os usos do patrimônio cultural. Segundo Goodey (2002a, p. 133):

Se quisermos, como muitos, que o mercado para o turismo cultural se expanda, teremos que fazer muito mais do que simplesmente abrir casas históricas e novas atrações, na expectativa de que os visitantes chegarão e apreciarão sua experiência.

Dessa forma, a concepção dos gestores e profissionais de planejamento sobre o que vem a ser o turismo cultural e todas as peculiaridades que envolvem a transformação de um patrimônio cultural em produto é fator fundamental para o desenvolvimento e a sustentabilidade da atividade econômica. 


\section{Planejamento interpretativo no turismo}

Os bens patrimoniais, para se tornarem atrativos no circuito do turismo cultural e para adquirirem valor, precisam ser interpretados dotando-se de novos significados, sendo essa interpretação fator central no planejamento da atividade como proposta de apreender as diversas leituras possíveis do patrimônio, promovendo múltiplos olhares sobre um mesmo fenômeno e gerando conhecimentos, sentimentos e atitudes. É por meio da interpretação que é possível ativar o patrimônio cultural:

A interpretação é entendida como a arte de dar a conhecer e tornar acessível o sentido e o significado dos bens culturais e dos modos de vida dos grupos humanos. É sempre um ato de comunicação que torna algo inteligível, mas que ao mesmo tempo converte o patrimônio cultural (e também o natural) em "ativo" da procura (também turística) (Pérez, 2009, p. 233).

0 desenvolvimento do turismo cultural depende de um planejamento que promova a ativação do patrimônio cultural e sua consequente valorização A inventariação dos recursos a serem interpretados, do mercado e do público-alvo, o desenho e a montagem da interpretação por meio da escolha de métodos e técnicas adequados à realidade local, a promoção e a gestão compõem as fases de um plano interpretativo que devem ser trabalhadas por uma equipe multidisciplinar de pesquisadores, sensíveis às peculiaridades da cultura local e à natureza das demandas dos turistas (Murta \& Goodey, 2002).

0 poder público e a população local devem ser parceiros na construção do planejamento interpretativo, promovendo uma gestão conjunta do patrimônio cultural, mas, se essa parceria não se efetivar, há o risco de o planejamento se transformar em um mero instrumento para a espetacularização da cultura para um mercado descomprometido com relação à sustentabilidade do patrimônio (Goodey, 2002b).

Há um desconhecimento de que consumo turístico de um espaço como atrativo cultural não depende apenas de seu valor artístico e histórico, mas de como se faz a gestão dos espaços de visitação (planos urbanísticos, planos de reabilitação urbana, instrumentos de planejamento territorial, entre outros), passando pela gestão dos fluxos de visitação (zoneamento, mobilidade), dos limites da capacidade de carga, da hospitalidade da população local, do tipo de oferta do atrativo turístico no universo virtual e da imagem construída (Donaire Benito, 2012; Ballart Hernández, 2005). A preocupação central do planejamento turístico deveria ser o de

[...] conciliar os diferentes usos e primar pela permanência das populações locais, observando as possibilidades de sobrevivência econômica e de acesso à moradia destas, sem excluir os visitantes, nem o caráter público dos bens tombados (Luchiari, 2005, p. 99).

Como afirma Pérez (2009, p. 238), “[...] a interpretação é um instrumento de planificação territorial, de definição de políticas de intervenção e de uso social do patrimônio cultural". Trata-se de um planejamento que requer habilidades para dotar de valores determinados elementos do espaço físico e os saberes e fazeres de um grupo. 0 planejamento interpretativo requer a compreensão de valores que vão além dos reconhecidos pelos arquivos da história oficial e da descrição simples da cultura local. A interpretação precisa ser construída a partir de relações com a população local e da compreensão de seu cotidiano.

Tendo como premissa a sensibilidade dos profissionais envolvidos com o planejamento do turismo, sua capacidade de se envolver, pesquisar e gerar empatia com a localidade, Murta e Goodey (2002) estabeleceram etapas a fim de orientar o desenvolvimento de um plano interpretativo, conforme descrito no Quadro 1. 
Quadro 1 - Ełapas para o desenvolvimento de um plano interpretativo

\begin{tabular}{|c|c|}
\hline $\begin{array}{l}1^{a} \text { etapa: inventário, registro de } \\
\text { recursos, temas e mercados }\end{array}$ & $\begin{array}{l}\text { - Registro de todos os recursos culturais e ambientais, técnicos e financeiros, } \\
\text { envolvendo, para tanto, diferentes setores da administração pública e da } \\
\text { comunidade. } \\
\text { - Estudo dos elementos a serem interpretados e dos potenciais a serem trabalhados } \\
\text { (temas, lendas, histórias, eventos, monumentos etc.). } \\
\text { - Caracterização das limitações da localidade quanto ao acesso e aos impactos } \\
\text { sobre o meio ambiente e a cultura. } \\
\text { - Identificação das limitações de gestão. } \\
\text { • Análise do perfil dos visitantes. } \\
\text { - Definição do público-alvo e dos mercados a serem atingidos. } \\
\text { Avaliação dos recursos financeiros disponíveis. }\end{array}$ \\
\hline $\begin{array}{l}2^{a} \text { etapa: desenho e } \\
\text { montagem da } \\
\text { interpretação. }\end{array}$ & $\begin{array}{c}\text { - Escolha dos meios e das técnicas de interpretação para uma localidade, tendo } \\
\text { como base a pesquisa sobre o público-alvo e o mercado. } \\
\text { - Estabelecimento da estratégia de comunicação com os visitantes, tendo como } \\
\text { base os princípios do que a comunidade deseja que os visitantes saibam, sintam } \\
\text { e façam na localidade. }\end{array}$ \\
\hline $\begin{array}{c}3^{a} \text { etapa: gestão e } \\
\text { promoção do patrimônio } \\
\text { cultural. }\end{array}$ & $\begin{array}{l}\text { - Definição dos meios e das técnicas de interpretação considerando a } \\
\text { interpretação ao vivo, textos, publicações e interpretação com base no design. } \\
\text { - Elaboração das estratégias interpretativas tomando como referência as } \\
\text { características culturais do lugar, de forma a valorizar e a intensificar a } \\
\text { experiência turística, podendo incluir trilhas e roteiros sinalizados, treinamento de } \\
\text { guias e condutores e publicações, como mapas ilustrados e folders. } \\
\text { - Avaliação contínua do produto e execução das readequações necessárias. } \\
\text { - Garantia da preservação e atualização das instalações interpretadas. }\end{array}$ \\
\hline
\end{tabular}

Fonte: Adaptado de Murta \& Goodey (2002, p. 22-24).

Um inventário do patrimônio cultural que exceda a atitude de mera catalogação e proporcione a compreensão dos saberes e fazeres e da relação da comunidade local com patrimônio constitui a etapa inicial de um plano interpretativo. Para Goodey (2002b, p. 55):

A essência do planejamento turístico local é que a comunidade, em todos os seus segmentos, tenha consciência de seu patrimônio, tanto do patrimônio material quanto do imaterial; que decida sobre aquilo que deseja compartilhar e o que deseja guardar só para si; e que escolha onde e como deseja que esta troca ocorra.

A relação da população local com os turistas deve ser harmônica e permitir o controle de possíveis impactos que podem ser ocasionados pelo desenvolvimento da atividade econômica. É fundamental, no processo, a definição da capacidade de carga de localidade, avaliando-se, em parceria com a comunidade local, os aspectos físicos, ambientais, econômicos, sociais, perceptivos e infraestruturais, conforme a natureza da proposta.

0 processo de planejamento interpretativo depende essencialmente de uma caracterização do perfil sociocultural do turista e de suas demandas. A faixa etária, o grau de instrução e o nível socioeconômico são fatores que interferem na formação do repertório desse turista, por meio do qual são definidas as formas de recepção da mensagem. A partir da compreensão das demandas de cada público, o desafio consiste em desenvolver técnicas para envolver todos os tipos de turista indiscriminadamente, incluindo os que não apresentam motivações essencialmente culturais. Nesse processo, a atuação dos profissionais de turismo constitui peça-chave:

Los profesionales en el turismo deben plantearse presentar el patrimonio, no a un turista cultural de amplio conocimiento y sensible a los valores de los bienes culturales, o a un turista de naturaleza preocupado por el medio ambiente, sino a un visitante que mira telenovelas y no documentales, el visitante "dominguero" a quien le interesa más el fútbol que los museos. Para todos ellos, la clave está en el lenguaje utilizado, en el dominio de ciertas técnicas interpretativas, pero sobre todo, en el arte de seducir a la audiência (Mendoza Ontiveros et al., 2011, p. 25). 
A capacitação desses profissionais para o trabalho com o turismo cultural é de importância central para o planejamento, e essa construção do produto turístico-cultural exige o domínio de técnicas específicas que Choay (2001) conceitua como engenharia cultural:

A metamorfose de seu valor de uso em valor econômico ocorre graças à engenharia cultural, vasto empreendimento público e privado, a serviço do qual trabalham grande número de animadores culturais, profissionais da comunicação, agentes de desenvolvimento, engenheiros, mediadores culturais. Sua tarefa consiste em explorar os monumentos por todos os meios, a fim de multiplicar indefinidamente o número de visitantes (Choay, 2001, p. 211).

0 cuidado com a construção, a seleção e a oferta de informações especializadas de contextos culturais específicos é primordial para o planejamento e o desenvolvimento do turismo cultural.

Deve-se capacitar pessoas para atuarem como intérpretes do bem cultural, bem como instrumentalizar instituições para a elaboração de projetos de interpretação patrimonial, de modo a facilitar e promover leituras significativas da história, do cotidiano e das manifestações culturais que envolvem os atrativos turísticos (Brasil, 2007, p. 27).

Para Murta \& Goodey (2002), a escolha dos meios e das técnicas de interpretação deve ter por base a pesquisa adequadamente estruturada e um bom design profissional, trazendo como princípio norteador três questões sobre a comunicação que se deseja estabelecer com os turistas: o que se quer que saibam? 0 que se quer que sintam? 0 que se quer que façam?

No processo de planejamento, é necessário um cuidado especial com a imagem do local, proporcionando informações com qualidade, que gerem expectativas no visitante que possam ser efetivamente atendidas e, principalmente, que estejam em conformidade com a imagem que a comunidade local deseja para si.

A avaliação permanente é fator estrutural no processo de planejamento interpretativo e deve ser constituída por estudos de recepção, que conduzam à compreensão de como os turistas e a população local estão interpretando o patrimônio cultural e de que forma essas relações estão sendo construídas. 0 produto turístico resultante de um planejamento interpretativo é totalmente relacional e em permanente processo de construção e reconstrução por meio das diferentes leituras realizadas pelos turistas e pela população local em vários cenários que se configuram e se reconfiguram de acordo com a conjuntura.

0 poder público desempenha um papel central no processo e deve atuar de forma regulatória, fornecendo condições estruturais para que o projeto se desenvolva adequadamente. A gestão do turismo precisa acontecer por meio de conselhos, fóruns, colegiados e demais instâncias de governança local que permitam a participação ativa de todos os membros interessados no turismo, lembrando que "[...] o planejamento público turístico deve defender os interesses de toda a comunidade e não apenas interesses turísticos setoriais de curto prazo" (Hall, 2001, p. 195). A sustentabilidade do planejamento interpretativo depende dessa capacidade de organização e mobilização da população local e de um trabalho conjunto com o poder público.

\section{Planejamento e desenvolvimento do turismo cultural em Penedo}

O Estado de Alagoas localiza-se na região Nordeste do Brasil, tem uma população de 3.120.494 habitantes (IBGE, 2010) e uma área de 27.848,14 km² composta de 102 municípios. Apresenta o pior Índice de Desenvolvimento Humano (IDH) do país $(0,63)$, com $47,9 \%$ da população na linha de pobreza (IPEA, 2012).

É o sexto maior produtor nacional de cana-de-açúcar, tendo a economia canavieira que domina os principais ramos produtivos e obstaculiza a entrada de outras atividades, configurando uma estrutura política de natureza oligárquica, reforçando a dominação local, o controle sobre a terra e o funcionamento da máquina estatal (Knupfer \& Assad, 2017). A história do Estado de Alagoas é de 
concentração do poder econômico em coronéis e usineiros que se revezavam no exercício da política, e, em muitos locais, essa prática ainda faz parte do cotidiano.

Contrapondo-se à primazia da economia canavieira, o turismo, em 2017, foi considerado a segunda maior atividade econômica e a que mais cresceu em Alagoas, que, por suas belezas naturais e seu patrimônio cultural, tem sido um dos destinos turísticos mais procurados da região Nordeste. Segundo a Secretaria de Estado do Turismo, o número de turistas internacionais cresceu $208 \%$ e de nacionais 74\%, em uma comparação de dados de 2017 com os de 2016 (Alagoas, 2017).

Alagoas conta com 62 municípios integrando o Mapa do Turismo Brasileiro, documento que funciona como base de orientação para o Ministério do Turismo no desenvolvimento de políticas públicas para o segmento. Em 2016, apenas 28 municípios faziam parte da lista, o que revela um crescimento de $121,42 \%$ e indica que, em todo o Estado, 62 cidades adotam o turismo como um dos principais fatores para desenvolver a economia local (Alagoas, 2017).

Mais de $90 \%$ dos turistas que visitam o Estado são atraídos para o litoral, sendo predominante o turismo de sol e praia, mas o Plano Estratégico de Desenvolvimento do Turismo e o Plano Estadual de Desenvolvimento trazem como meta o fomento ao turismo cultural.

Penedo é um dos 62 municípios que compõem o Mapa do Turismo Brasileiro, com potencial para o desenvolvimento do turismo cultural, mas nunca esteve incluído em roteiros turísticos consolidados no Estado de Alagoas, pois suas condições não permitiram que fosse considerado, pelos próprios critérios do Ministério do Turismo, como um município turístico, mas apenas um município com potencial para o turismo $^{3}$. Não há um fluxo de turistas, os meios de hospedagem são poucos e apresentam serviços precários, com taxa de ocupação próxima a zero aos finais de semana e feriados. Em Penedo, não há empreendedores ou grupos organizados no turismo que se mobilizem e apresentem condições de concorrer com o mercado consolidado de turismo de sol e praia (Silva, 2016).

O município de Penedo apresenta um cenário de miséria e exclusão social, com um IDH de 0,63, e $20,6 \%$ da sua população se encontra entre a linha da indigência e da pobreza e 17,8\% abaixo da linha da indigência (IPEA, 2012). 0 índice de analfabetismo é de 29,3\% entre os que têm 15 anos ou mais de idade (IBGE, 2010). A maioria da população vive de rendas de programas do governo federal ou trabalha, de forma sazonal, com a colheita de cana-de-açúcar.

A exclusão social da população está intimamente relacionada à exclusão política e é um fator que precisa ser considerado quando se faz referência ao planejamento participativo e ao próprio exercício da democracia.

Uma participação política ativa pode estar fora do alcance dos indivíduos socialmente excluídos, aos quais podem faltar informações, as oportunidades e os recursos necessários para o envolvimento no processo político (Giddens, 2005, p. 265).

Para analisar um processo de planejamento e seus entraves, é necessário compreender as condições socioculturais da população local e sua estreita relação com as configurações de poder. A transformação do espaço em atrativo cultural é permeada por múltiplos conflitos entre diferentes atores sociais, que apresentam interesses diversos, muitas vezes divergentes, sendo que o patrimônio é espaço de disputa econômica, política e simbólica (Canclini, 1994). 0 planejamento, por sua vez, ocorre

[...] sobre um espaço concreto, herdado, histórica e socialmente construído e que, portanto, tem de ser considerado pela política pública e pelos programas e projetos que dela derivam (Cruz, 2005, p. 40).

A partir da análise de conteúdo dos documentos e dos discursos das respostas das entrevistas realizadas, conforme já descrito na metodologia deste artigo, foi possível mapear uma multiplicidade de

\footnotetext{
${ }^{3}$ Município turístico: “[...] aquele que possui atrativo turístico, infraestrutura, produtos e serviços adequados que atendam ao fluxo existente”. Município com potencial turístico: “[...] aquele que possui recursos turísticos sem infraestrutura, produtos e/ou serviços consolidados" (Brasil, 2006).
} 
elementos que entravam o processo de planejamento e desenvolvimento do turismo cultural, sendo que quatro fatores, elencados a seguir, destacam-se como centrais em Penedo.

\section{Ausência de um projeto de educação patrimonial}

As escolas municipais têm a história de Penedo como disciplina integrando o currículo obrigatório, mas não há material para subsidiar o trabalho dos professores, os quais não têm conhecimento e formação para trabalhar a história da cidade e tampouco colocar um projeto de educação patrimonial, com sua complexidade e dimensão, em prática.

A educação patrimonial conceituada pela Portaria no 137, de 28 de abril de 2016, do IPHAN como

[...] processos educativos formais e não formais, construídos de forma coletiva e dialógica, que têm como foco o patrimônio cultural socialmente apropriado como recurso para compreensão sócio histórica das referências culturais, a fim de colaborar para seu reconhecimento, valorização e preservação (IPHAN, 2016, s/p),

passa por um esvaziamento de sentido, quando reduzida a uma aula de história, uma palestra ou um evento pontual, desvinculada de um projeto mais amplo.

Diante do tema da educação patrimonial, todos os entrevistados se referiram à problemática da ausência de pertencimento com Penedo por parte da população local. A população não conhecia seu patrimônio cultural e não apresentava relações de pertencimento e muito menos reconhecimento da necessidade de preservação e do valor que tal patrimônio podia significar para o desenvolvimento do turismo. A maioria não conseguia dimensionar alternativas para se inserir como ator na atividade econômica do turismo.

Em pesquisa realizada em 2013 com moradores do centro histórico do município, verificou-se que $43 \%$ da população era contra o tombamento e $7 \%$ não tinham nem mesmo uma opinião formada, desconhecendo o que o processo significa. A maioria se opunha a lei que proibia alterações estruturais em imóveis residenciais no centro histórico, sendo que a demanda de adequar a casa às próprias necessidades cotidianas se sobrepõe ao desejo de preservação do patrimônio que é quase inexistente (Ramos, 2015).

Verifica-se também um sentimento de adversidade contra o próprio IPHAN, que é visto como um órgão que pune, multa em caso de alteração do imóvel, propõe projetos considerados desnecessários e que "emperra" o desenvolvimento do município.

\section{Inoperância das instâncias de governança}

O FUNPATRI, espécie de conselho com várias representações do poder público, população local e mercado turístico, foi constituído como um processo formal, obrigatório para o desenvolvimento do Programa Monumenta em 2004, mas sem histórico de atuação, decisão ou qualquer ação que possa caracterizar uma gestão participativa no turismo cultural, ou mesmo decisões sobre alterações que foram realizadas com relação à parte estrutural ou aos usos do patrimônio cultural.

O COMTUR foi constituído no final 2014, e seu histórico até 2018 era de poucas reuniões, todas com baixo quórum e sem encaminhamentos efetivos. Os representantes do COMTUR apontaram nas entrevistas que não havia articulação direta de suas propostas e discussões com as ações do PAC-CH nem com gestão do FUNPATRI e que as ações propostas no Plano Estratégico de Desenvolvimento do Turismo, no que se refere ao turismo cultural, não se constituíam em pauta de discussões ou compunham agendas.

Ambas as instâncias eram praticamente inoperantes e não participavam da gestão de ações efetivamente executadas no município. A população (98\%) declarou que nunca participou de reuniões 
para discussão do turismo e do patrimônio em Penedo, desconhecia a existência do FUNPATRI, do COMTUR ou de qualquer outro órgão que pudesse representá-los (Ramos, 2015).

Os representantes do trade turístico, nos respectivos conselhos, revelaram que um problema central no planejamento do turismo era a ausência de articulação com a gestão pública, que, por sua vez, também não se articulava com a população local, o que inviabilizava um planejamento conjunto participativo, elemento reconhecido por todos como central para o planejamento e o desenvolvimento do turismo cultural.

\section{Desconhecimento por parte da Gestão Pública das peculiaridades do Planejamento do Turismo Cultural}

A partir dos discursos dos gestores das secretarias de Turismo, Cultura, Planejamento e Infraestrutura, evidencia-se que a equipe de gestão pública desconhecia completamente o processo de planejamento do turismo cultural, ignorava a necessidade de um planejamento interpretativo e reduzia o desenvolvimento turístico do município à atratividade gerada pela revitalização dos bens imóveis, sem habilitação de novos usos.

Os gestores do IPHAN em Penedo reconheceram, na resposta das entrevistas, a problemática desse desconhecimento das peculiaridades do turismo cultural em seu próprio trabalho com a preservação do patrimônio cultural. O IPHAN não articulou, na execução de suas ações, o Programa Monumenta com o processo de desenvolvimento do turismo cultural como elemento necessário para a sustentabilidade do patrimônio cultural e continuou fazendo o mesmo no processo de execução das ações do PAC-CH.

Verificou-se que não havia uma equipe técnica com a expertise necessária, nem no IPHAN, nem nas gestões municipais em Penedo, que revelasse habilidades e competências para desenvolver um trabalho com o turismo cultural.

\section{O mercado de turismo em Alagoas é consolidado em "sol e praia"}

Em 2016, 10\% do PIB do Estado de Alagoas adveio do turismo, tratando-se de um mercado consolidado em roteiros sol e praia que envolve grupos hegemônicos atuantes na atividade econômica, com representação no processo de planejamento e gestão, articulados e mobilizados para garantir seus interesses.

Em Penedo, não havia empreendedores ou grupos organizados no turismo que se mobilizassem e apresentassem condições mínimas de concorrência com as estruturas desse mercado consolidado. No Plano Estratégico de Desenvolvimento Municipal do Turismo, essa ausência de empreendedores foi retratada entre os aspectos negativos elencados, como "falta de espírito empreendedor" (Penedo, 2014), cuja principal solução apontada seria a ampliação do acesso à educação, ignorando a necessidade de conhecimento do contexto de desenvolvimento da atividade econômica no Estado de Alagoas e da constituição de estratégias para um trabalho efetivo com as adversidades presentes no cenário para o desenvolvimento do turismo.

Verificou-se que nunca houve um plano que, efetivamente, apresentasse, entre seus objetivos, o desenvolvimento do turismo cultural na cidade, mas apenas o desenvolvimento de um programa de revitalização de bens imóveis, absolutamente desarticulado de qualquer proposta que pudesse valorizar esse patrimônio e torná-lo atrativo.

\section{Considerações finais}

O desenvolvimento do turismo cultural depende de um processo de planejamento interpretativo que proporcione o uso turístico do patrimônio cultural, valorizando-o com a proporção de vivências e experiências diferenciadas ao turista. É necessário o envolvimento da população local com o patrimônio, de forma que essa interpretação ocorra em consonância com um sentimento de valorização 
e preservação e que essa população possa ser um agente de decisões e controle sobre os recursos e os impactos que venham a ser ocasionados pelo turismo.

Por sua vez, o poder público deve ser parceiro da população em um processo de planejamento e gestão conjunta do turismo cultural, ampliando os espaços de discussão sobre a atividade econômica e a autonomia de fóruns, conselhos e demais instâncias de representação.

Em Penedo, é possível perceber que há uma proposta de desenvolvimento do turismo cultural como elemento para sustentabilidade do patrimônio cultural revitalizado pelo Programa Monumenta e pelo PAC-CH, mas essa proposta nunca se consolidou efetivamente em um processo de planejamento por causa: da ausência de projetos de educação patrimonial para uma população que desconhece seu patrimônio, é contrária ao tombamento do centro histórico e não tem consciência de como pode se inserir na atividade econômica do turismo; da inabilidade da gestão pública, municipal e estadual e do próprio IPHAN, que desconhece as peculiaridades do turismo cultural e não apresenta uma equipe técnica qualificada para realização de um planejamento interpretativo; de um mercado consolidado de turismo de sol e praia no Estado de Alagoas, com grupos hegemônicos no controle, com qual é muito difícil competir; e da inoperância das instâncias de governança local, que revela a falta de condições para um planejamento democrático e participativo.

Dessa forma, verifica-se que os recursos investidos tanto pelo PAC-CH como pelo Programa Monumenta estão se perdendo, sem perspectivas de se tornarem fomento para o desenvolvimento socioeconômico do município, na medida em que a sustentabilidade do patrimônio revitalizado fica cada vez mais distante da realidade, uma vez que o projeto do turismo cultural foi reduzido à mera revitalização dos bens imóveis, sem preocupação com a habilitação dos novos usos do patrimônio cultural e sua interpretação.

\section{Referências}

Alagoas. Secretaria de Desenvolvimento Econômico e Turismo. (2017). Mapa do Turismo de Alagoas cresce 139\% em comparação ao mesmo período do ano passado. Recuperado em 2 de janeiro de 2018, de http://www.sedetur.al.gov.br/noticia/item/1915-mapa-do-turismo-de-alagoas-cresce-139-em-comparacao-aomesmo-periodo-do-ano-passado

Ballart Hernández, J. (2005). Patrimonio Cultural y Turismo Sostenible en el espacio Iberoamericano: retos y oportunidades del presente. Diálogos: Revista do Departamento de História e do Programa de Pós-graduação em História, 9(1), 11-25.

Beni, M. C. (2004). Turismo: da economia de serviços à economia da experiência. Turismo-Visão e Ação, 6(3), 295306.

Brasil. Ministério do Turismo. (2006). Projeto Inventário da oferta Turística. Programa de Regionalização do Turismo. Recuperado em 8 de agosto de 2013, de http://www.inventario.turismo.gov.br/invtur/downloads/projInvtur/projInvtur.pdf

Brasil. Ministério do Turismo. (2007). Turismo cultural: diretrizes para o desenvolvimento (pp. 1-36). Recuperado em 01 de março de 2016, de http://nute.ufsc.br/bibliotecas/upload/diretrizesturismo_cultural.pdf

Brasil. Ministério do Planejamento. (2009). PAC: cidades históricas. Recuperado em 20 de maio de 2014, de http://www.pac.gov.br/cidade-melhor/pac-cidades-historicas

Brasil. Ministério do Turismo. Secretaria Nacional de Políticas de Turismo. Departamento de Estruturação, Articulação e Ordenamento Turístico. Coordenação-Geral de Segmentação. (2010). Turismo Cultural: orientações básicas. Brasília: Ministério do Turismo.

Brasil. Ministério da Cultura. (2012). Programa Monumenta. Recuperado em 20 de maio de 2014, de http://www.monumenta.gov.br/site/?page_id=164 
Brasil. Ministério do Turismo. (2014). Economia da experiência. Recuperado em 30 de março de 2014, de http://www.turismo.gov.br/turismo/programas_acoes/regionalizacao_turismo/economia_experiencia.html

Canclini, N. G. (1994). 0 patrimônio cultural e a Construção Imaginaria do Nacional. Revista de Patrimônio Histórico e Artístico Nacional, 23, 95-115.

Castriota, L. B., Araujo, G. M., Cardoso, K., \& Sousa, V. P. (2010). PAC Cidades Históricas: oportunidade para a conservação integrada? Locus: Revista de História, 16(2), 93-117.

Conselho Internacional de Monumentos e Sítios Históricos - ICOMOS. (1999). Carta internacional sobre turismo cultural. Recuperado em 15 de março de 2016, de http://www.icomos.org/charters/tourism_sp.pdf

Craik, J. (1997). The culture of tourism. In C. Rojek, \& J. Urry (Eds.), Touring cultures, transformations of travel and theory (pp. 114-136). New York: Routledge.

Cruz, R. (2005). Políticas Públicas de Turismo no Brasil: território usado, território negligenciado. Revista Geosul, $20(40), 27-45$.

Choay, F. (2001). A alegoria do Patrimônio. São Paulo: Unesp.

Diégues, M. D., Jr. (2006). O Bangüê nas Alagoas: traços da influência do sistema econômico do engenho de açúcar na vida e na cultura regional. Maceio: Edufal.

Donaire Benito, J. A. (2012). Turismo cultural: entre la experiencia y el ritual. Girona: Ediciones Vitella.

Giddens, A. (2005). Pobreza, previdência social e exclusão social. In A. Giddens, Sociologia. Porto Alegre: Artmed.

Goodey, B. (2002a). Turismo cultural: novos viajantes, novas descobertas. In S. M. Murta, \& C. Albano (Eds.), Interpretar o Patrimônio: um exercício do olhar (pp. 131-138). Belo Horizonte: UFMG.

Goodey, B. (2002b). Interpretação e comunidade local. In: S. M. Murta, \& C. Albano (Eds.), Interpretar o Patrimônio: um exercício do olhar (pp. 47-58). Belo Horizonte: UFMG.

Hall, C. M. (2001). Planejamento turístico: políticas, processos e relacionamentos. São Paulo: Contexto.

Instituto Brasileiro de Geografia e Estatística - IBGE. (2010). IBGE Cidades: Brasil/Alagoa/Penedo. Recuperado em 10 de abril de 2016, de https://cidades.ibge.gov.br/brasil/al/penedo/panorama

Instituto do Patrimônio Histórico e Artístico Nacional - IPHAN. (2016, 29 de abril). Portaria no 137, de 28 de abril de 2016. Estabelece diretrizes de educação patrimonial no âmbito do Iphan e das Casas do Patrimônio. Brasília: Diário Oficial da União, seção 1.

Instituto de Pesquisa Econômica Aplicada - IPEA. (2012). Situação social nos Estados: Alagoas. Brasília: IPEA.

Knupfer, M. E., \& Assad, I. T. (Eds.). (2017). Plano de desenvolvimento estadual de Alagoas. Brasília: IABS.

Luchiari, M. T. D. P. (2005). A reinvenção do patrimônio arquitetônico no consumo das cidades. GEOUSP: Espaço e Tempo, 17, 95-105.

Mendoza Ontiveros, M. M., Umbral Martínez, M. E., \& Arévalo Moreno, M. N. (2011). La interpretación del patrimonio, una herramienta para el profesional del turismo. El Periplo Sustentable, (20), 9-30. Recuperado em 5 de abril de 2018, de http://www.redalyc.org/pdf/1934/193417856002.pdf

Minayo, M. C. S. (1994). O desafio do conhecimento: pesquisa qualitativa em saúde (2. ed.). São Paulo: Hucitec/Abrasco.

Murta, S. M., \& Goodey, B. (2002). Interpretação do patrimônio para visitantes: um quadro conceitual. In S. M. Murta, \& C. Albano (Eds.), Interpretar o patrimônio: um exercício do olhar (pp. 13-46). Belo Horizonte: UFMG.

Organização Mundial do Turismo - OMT. (2001). Introdução ao turismo. São Paulo: Roca.

Penedo. Prefeitura Municipal. (2014). Plano de Diretrizes Estratégicas para o Turismo do Município de Penedo - Alagoas. Penedo: Secretaria de Desenvolvimento Econômico, Industria, Comércio, Meio Ambiente, Ciência e Tecnologia.

Pérez, X.P. (2009). Turismo cultural: uma visão antropológica. Tenerife: Aca y Pasos, RTPC. 
Ramos, S. P. (2015). Apontamentos sobre a insustentabilidade de um Programa Político: o caso do Programa Monumenta em Penedo-AL. Revista Iberoamericana de Turismo, 5, 148-168. Recuperado em 15 de março de 2016, de http://www.seer.ufal.br/index.php/ritur/article/view/1697/1233

Rifkin, J. (2001). A era do acesso. São Paulo: Makron Books.

Sánchez, F. (1999). Buscando um lugar ao sol para as cidades: o papel das atuais políticas de promoção urbana. Revista Paranaense de Geografia, 4. Recuperado em 15 de março de 2016, de www.agbcuritiba.hpg.ig.com.br/Revistas/Rpg3/4fernanda.htm

Santana Talavera, A. (2003). Patrimonios culturales y turistas: unos leen lo que otros miran. Pasos. Revista de Turismo y Patrimonio Cultural, 1(1), 1-13.

Silva, D. P. S. (2016). Arruando" vejo rio, homens, pedra \& cal: a des-re-patrimonialização do sítio histórico tombado de Penedo-AL (Tese de doutorado). Pós-graduação em Geografia, Universidade Federal de Sergipe, São Cristóvão.

Editor: Rodrigo Firmino.

Recebido: Abr. 20, 2018

Aprovado: Dez. 03, 2018 